\title{
PSEUDOHYPOPARATHYROIDISM IN INFANCY
}

\author{
BY \\ L. S. TAITZ* \\ From the Department of Paediatrics, Coronation Hospital, Johannesburg
}

(RECEIVED FOR PUBLICATION FEBRUARY 10, 1960)

Although many of the previously reported cases of this rare condition have occurred in childhood it has not previously been diagnosed during the first year of life, despite the fact that symptoms may begin in infancy (Peterman and Garvey, 1949; MacGregor and Whitehead, 1954; Cusmano, Baker and Finby, 1956). The following report records the youngest example of pseudohypoparathyroidism yet reported.

\section{Case Report}

M.M., a coloured male infant, was first investigated in the Paediatric Section, Coronation Hospital, at the age of 3 months, for convulsions which had commenced a week before admission. There was no history of birth trauma, neonatal jaundice or epilepsy in the family. Before the onset of the fits the child had been perfectly well. Until the age of 2 months he had been breast fed and this was followed by powdered whole cow's milk reconstituted to a dilution of three parts milk to one part water with added sucrose. Lumbar puncture, skull and chest radiographs, Wassermann reaction and serum electrolytes were all normal with the exception of the serum calcium which was found to be $3.0 \mathrm{mEq}$./l. (6 mg. \%). The child was diagnosed as having hypocalcaemic tetany and discharged on a maintenance dose of vitamin D (shark liver oil) 3,000 units daily.

Three weeks following discharge the fits recurred and the infant was readmitted for investigation.

Examination revealed an underweight male infant weighing $7 \mathrm{lb} .8 \mathrm{oz}$. in a state of continuous tetany. There was pallor of the conjunctivae and mucus membranes. There was no evidence of nuchal rigidity and the head circumference was $14 \cdot 5$ in. Both Chvostek and Trousseau signs were strongly positive. Examination of the heart, lungs and abdomen revealed no abnormalities. Notable features were the short stubby fingers and toes and the round contour of the face.

The mother and grandmother of the child were both of markedly short stature (4 ft. 8 in.), but neither showed any abnormalities of the digits. There was one sibling, a girl aged 3 years, who was quite normal. Blood calcium and phosphorus estimations on the three subjects were within normal limits. No other member of the family was accessible for study.

\footnotetext{
* Present address: Department of Paediatrics, Baragwanath Hospital, Johannesburg.
}

Special Investigations. Radiographs of the skull, chest and long bones revealed gross demineralization of the entire skeleton. There was no evidence of intracranial or subcutaneous calcification.

Estimations on the blood revealed a mild hypochromic anaemia (Hb 9.6 g. \%); the blood urea nitrogen was $38 \mathrm{mg} . \%$ and the serum sodium, potassium and chlorides were within normal limits. The Wassermann reaction was negative. Protein electrophoresis of the serum revealed no abnormalities. The urine contained neither albumin nor reducing substance. Microscopic examination of a centrifuged specimen revealed nothing of note. There was no excess of amino acids on chromatographic analysis. Estimations of the 24 hour excretion of both calcium and phosphorus were extremely low, the former varying between 9 and $12 \mathrm{mg}$. daily and the latter between 180 and $400 \mathrm{mg}$. daily. The $p \mathrm{H}$ of the urine was acid.

The serum calcium was $3 \cdot 2 \mathrm{mEq} . / 1$. and the plasma phosphorus was $5 \cdot 2 \mathrm{mg}$. \%. The alkaline phosphatase was 23 King-Armstrong units.

Fat studies of the stools revealed no evidence of malabsorption.

Progress. After obtaining a baseline of blood calcium, phosphorus and alkaline phosphatase levels the patient was treated with 5,000 units of vitamin D daily with no improvement.

Several attempts were made to perform the EllsworthHoward test but these were frustrated by the inability to obtain suitable urine specimens. The patient was then given 100 units of parathormone (Lilly) every eight hours for four days with no significant rise in the serum calcium level. This particular batch of hormone had produced a phosphate diuresis in the control subject for the Ellsworth-Howard test.

Throughout the entire period of observation (Fig. 1) the serum calcium remained below normal and the patient was subject to repeated attacks of tetany until treated with dihydrotachysterol (AT10 Bayer) $3 \mathrm{ml}$. daily with added calcium supplements. Thereafter the serum calcium rose steadily to normal levels which were maintained. This was associated with a fall in the plasma phosphorus.

\section{Discussion}

The diagnosis in this case rests on the failure of parathyroid hormone administered parenterally to 


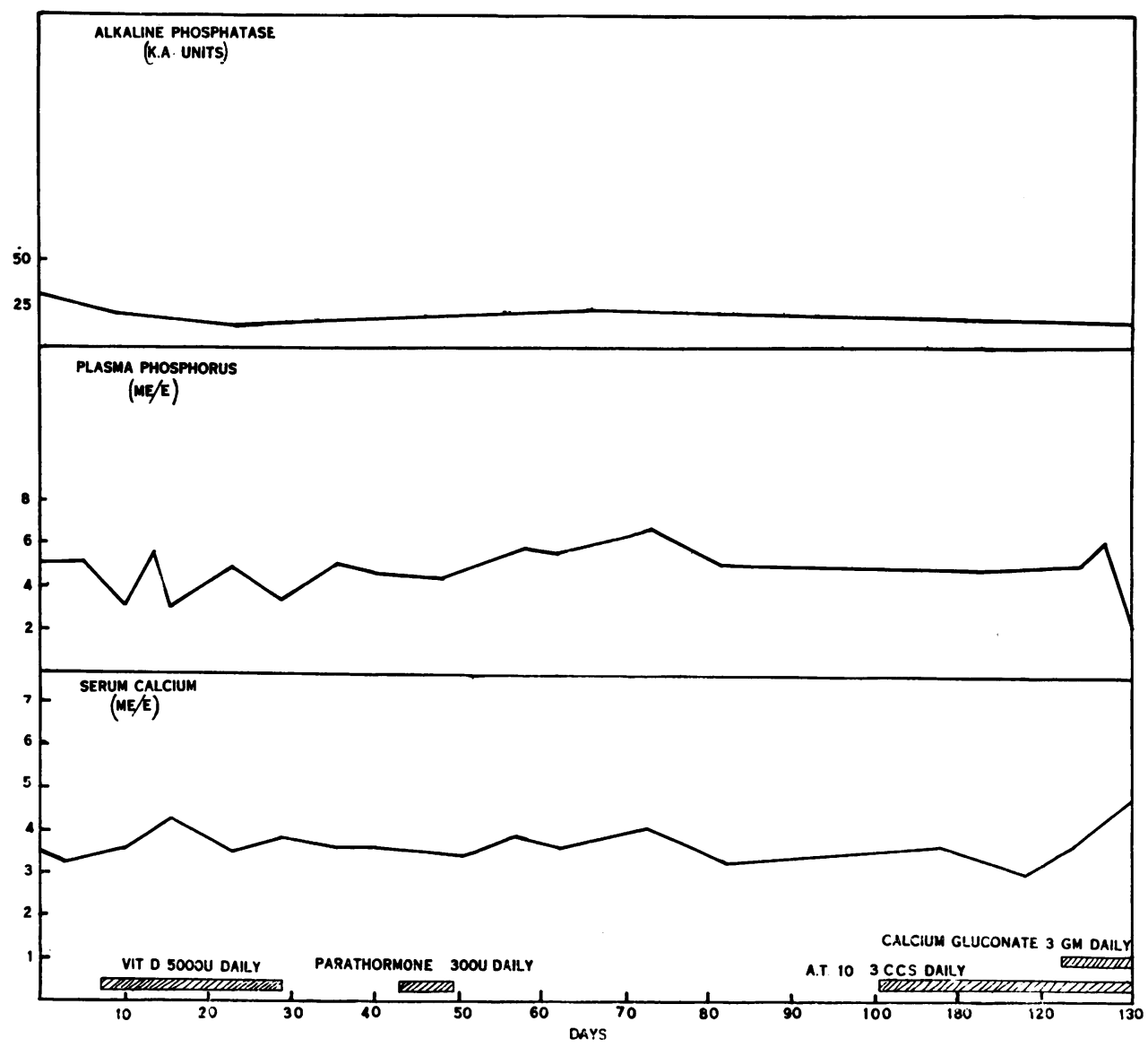

FIG. 1.-Serum calcium, plasma phosphorus and alkaline phosphatase levels and response to treatment.

produce a rise in the serum calcium with a concomitant fall in the phosphorus level. It was found impossible to collect the hourly specimens required for the Ellsworth-Howard test, the diagnostic procedure originally advocated by Albright, Burnett, Smith and Parson (1942). However, recently, workers have cast doubt on the validity of the procedure and suggest that the response of the serum calcium and phosphorus levels to parathyroid hormone over a definite period of time is a more reliable method of assessing tissue response to parathyroid (Dent, Bishop and de Mowbray, 1953; MacGregor and Whitehead, 1954; Wilkins, 1957). It is thus felt that the diagnosis in this case is valid in spite of the inability, for technical reasons, to demonstrate the classical absence of phosphorus diuresis.

Chief interest in this case lies in the youth of the patient. Many of the previously reported cases had undergone irreversible changes including cataracts, mental deficiency and subcutaneous and intracranial calcification. Our patient-was quite free of these stigmata. It seems, at least, likely that some of these sequelae might be averted if cases were diagnosed early and effective treatment instituted before changes occurred.

Of considerable interest is the presence in this patient of skeletal decalcification. Eight similar cases have been collected from the literature and it appears likely that they form a definite entity. In many of this group, demineralization of the bones with symmetrical shortening of the metacarpals is the dominant radiographic finding (Peterman and Garvey, 1949; Elrick, Albright, Bartter, Forbes and Reeves, 1950; Reynolds, Jacobson, Edmondson, Martin and Nelson, 1952; MacGregor and Whitehead, 1954; Prentice, 1954; Frame and Carter, 1955; Oberst and Tompkins, 1955; Jackson, Hoffenberg, Linder and Irwin, 1956). This, together with the low serum calcium levels suggests that there is a 
generalized depletion of the total body calcium which cannot be accounted for by the accepted theory that there is a failure of tissue response to parathyroid hormone. In addition, this depletion cannot be explained by the ectopic areas of calcification. It seems likely that there is, in addition to the failure of parathyroid response, either decreased absorption of calcium from the gastrointestinal tract or excessive loss in the urine. It is known, however, that urinary loss of both calcium and phosphorus is extremely low in these cases. Furthermore, nephrolithiasis has not been described as a complication. One must conclude therefore that calcium absorption is impaired. It is also of interest that some cases of pseudo-hypoparathyroidism require additional calcium supplements as well as AT10 or massive doses of calciferol in order to raise the serum calcium to normal levels. The present patient shows this feature. Despite the fact that he was receiving three times the recommended adult dose, it was only when oral calcium gluconate was added to the regimen that the serum calcium responded. That this defect is not due to vitamin $\mathrm{D}$ deficiency is indicated by the raised plasma phosphorus in these cases and the normal alkaline phosphatase. It seems possible that there is, in these patients, a selective block to the absorption of calcium from the gastro-intestinal tract. It is suggested that this might take the form of an additional enzyme defect in the intestinal mucosa, resulting in the defective absorption of calcium. The exact nature and existence of this defect can only be elucidated by calcium balance studies.

\section{Summary}

Pseudohypoparathyroidism is described in a 4-month-old infant.

The presence of generalized decalcification of the skeleton is noted and eight similar cases collected from the literature.

It is suggested that in addition to the failure of tissue response to parathyroid hormone there is an additional enzyme defect present, manifesting as an impairment of absorption of calcium from the gastro-intestinal tract.

I wish to thank Dr. Harold Falcke and Dr. Harvey Cohen, Paediatricians at Coronation Hospital, and Dr. O. Elliot, Superintendent at Coronation Hospital, for permission to publish this case and the Photographic section, Department of Medicine, University of the Witwatersrand for the Figure.

\section{REFERENCES}

Albright, F., Burnett, C. H., Smith, P. H. and Parson, W. (1942), Pseudo-hypoparathyroidism; an example of 'Seabright-Bantam' syndrome. Report of three cases. Endocrinology 30, 922.

Cusmano, J. V., Baker, D. H. and Finby, N. (1956). Pseudohypoparathyroidism. Radiology, 67, 845.

Dent, C. E., Bishop, P. M. F. and de Mowbray, R. R. (1953). Pseudohypoparathyroidism. Proc. roy. Soc. Med., 46, 291.

Elrick, H., Albright, F., Bartter, F. C., Forbes, A. P. and Reeves, J. D.' (1950). Further studies on pseudo-hypoparathyroidism. Report of four new cases. Acta endocr. (Kbh.), 5, 1991.

Frame, B. and Carter, S. (1955). Pseudohypoparathyroidism. Neurology, 5, 297.

Jackson, W. P. U., Hoffenberg, R., Linder, G. C. and Irwin, L. (1956). Syndrome of steatorrhea, pseudohypoparathyroidism and amenorrhea. J. clin. Endocr., 16, 1043.

MacGregor, M. E. and Whitehead, T. P. (1954). Pseudo-hypoparathyroidism. Arch. Dis. Childh., 29, 398.

Oberst, B. B. and Tompkins, C. A. (1955). Pseudohypoparathyroidism. A.M.A. Amer. J. Dis. Child., 90, 205.

Peterman, M. G. and Garvey, J. L. (1949). Pseudohypoparathyroidism: Case report. Pediatrics. 4, 790.

Prentice, R. J. (1954). Pseudohypoparathyroidism: A case report. J. clin. Endocr., 14, 1069.

Reynolds, T. B., Jacobson, G., Edmondson, H. A., Martin, H. E. and Nelson, C. H. (1952). Pseudohypoparathyroidism; Report of a case showing bony demineralization. Ibid., 12, 560 .

Wilkins, L. (1957). The Diagnosis and Treatment of Endocrine Disorders in Childhood and Adolescence. 2nd ed. Thomas, Springfield, Illinois. 